\title{
Development of a novel disposable lid speculum with a drape
}

This article was published in the following Dove Press journal:

Clinical Ophthalmology

2 August 2013

Number of times this article has been viewed

Toru Urano'

Masataka Kasaoka'

Ryoji Yamakawa'

YukihikoTamai $^{2}$

\section{Shoichiro Nakamura ${ }^{2}$}

'Department of Ophthalmology,

Kurume University School

of Medicine, Kurume, Japan;

${ }^{2}$ Hakko Co, Ltd, Nagano, Japan

\section{Video abstract}

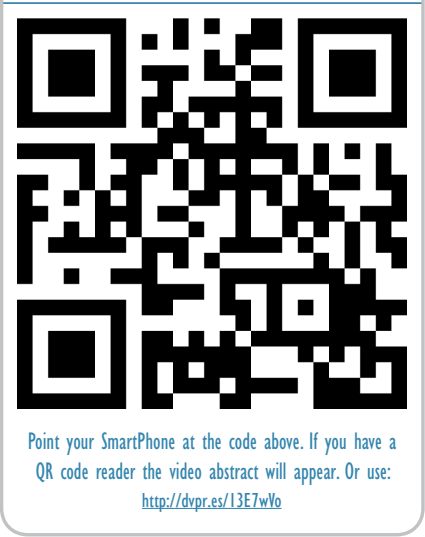

Correspondence: Toru Urano

Department of Ophthalmology,

Kurume University School of Medicine,

67 Asahi-machi, Kurume 830-00II, Japan

Tel 8 I 9 423। 7574

Fax 8I 942370324

Email kimidori.u@gmail.com
Purpose: To evaluate the clinical use of a newly-developed disposable lid speculum with a drape.

Methods: LiDrape ${ }^{\circledR}$ is a cylindrical device that consists of two flexible rings of polyacetal resin with a transparent elastic silicone sheet attached to the rings. The novel device holds the eyelids between the rings, and a hole in the center of the device provides a surgical field. We used the novel device in cataract surgery (75 eyes), glaucoma surgery (eleven eyes), vitrectomy (ten eyes), and intravitreal injection (six eyes) and evaluated its clinical efficacy.

Results: The LiDrape was easy to attach and detach. The novel device was not detached from the eye during surgery. No eyelashes or secretions from the meibomian glands were seen in the surgical field, and the drape provided a sufficient surgical field.

Conclusions: The LiDrape functions as a lid speculum as well as a drape. Our results showed that the novel device is useful for ocular surgeries.

Keywords: LiDrape, lid speculum, drape, endophthalmitis

\section{Introduction}

Postoperative endophthalmitis is a devastating complication of ocular surgery. The incidence of endophthalmitis after extracapsular cataract extraction, pars plana vitrectomy, penetrating keratoplasty, or glaucoma filtering surgery has been reported to be $0.051 \%$ to $0.30 \% .{ }^{1}$ Speaker et al demonstrated that an organism isolated from the vitreous was genetically indistinguishable from an isolate recovered from the patient's eyelid, conjunctiva, or nose in $82 \%$ of their cases of endophthalmitis. ${ }^{2}$ It is believed that postoperative endophthalmitis is caused by the patient's own flora from the eyelids and conjunctival sac that is infiltrated into the eye through the surgical field. It is therefore necessary to minimize preoperative and intraoperative contamination of the surgical field.

The currently used prophylactic measures against endophthalmitis are applications of preoperative topical antibiotics, ${ }^{3,4}$ preoperative povidone-iodine antisepsis, ${ }^{5,6}$ proper application of a drape, ${ }^{7,8}$ a sclerocorneal incision,,${ }^{9,10}$ an injectable lens, ${ }^{11}$ and intracameral injection of antibiotics at the end of surgery. ${ }^{12,13}$

Proper application of a drape isolates the lid margin, skin, and the lashes from the operative field and prevents bacteria from gaining access to the operative field..$^{7,8}$ However, it is difficult to completely drape the eyelids and eyelashes around the medial and lateral canthi with a conventional sticky drape. The adherence of a surgical drape to the atopic skin is usually poor, and a conventional drape can easily detach from the skin of patients with atopic dermatitis during the surgery. We developed a disposable 
lid speculum with a drape (LiDrape ${ }^{\circledR}$ Hakko Co, Ltd, Nagano, Japan) that can easily and completely drape the eyelashes and eyelids and provide a sufficient surgical field.

\section{Subjects and methods}

The LiDrape is a cylindrical device that consists of two flexible rings of polyacetal resin attached with a transparent elastic silicone sheet. The novel device holds the eyelids between the rings, and a hole in the center of the device provides a surgical field. The diameter of the upper ring is $58 \mathrm{~mm}$, and the diameter of the bottom ring can be $22 \mathrm{~mm}$, $23 \mathrm{~mm}, 24 \mathrm{~mm}, 25 \mathrm{~mm}, 26 \mathrm{~mm}, 27 \mathrm{~mm}$, or $28 \mathrm{~mm}$. The device functions as a speculum as well as a drape (Figures 1 and 2). With the novel device, draping and speculum placement are performed at one time.

After approval from the Kurume University Institutional Review Board, informed consent was obtained from each patient. We used the novel device in cataract surgery ( 75 eyes of 70 patients; 28 men and 42 women; mean age: 70 years; range: 15 to 92 years), glaucoma surgery (eleven eyes of eleven patients; seven men and four women; mean age: 64 years; range: 35 to 85 years), 23-gauge vitrectomy (ten eyes of ten patients; two men and eight women; mean age: 66 years; range: 54 to 85 years), and in intravitreal injection of anti-vascular endothelial growth factor (anti-VEGF) antibody (six eyes of six patients; one man and five women; mean age: 68 years; range: 61 to 74 years), between October 2007 and April 2010, and we evaluated the clinical efficacy, including the selection of the device size, attachment procedure, and surgical maneuver. We also evaluated the effectiveness of the device in patients with atopic dermatitis.

\section{Results}

\section{Size selection}

The selection of the proper LiDrape size for each patient is important. The width of the palpebral fissure and the depth of the conjunctival sac are different in each person. The size of the bottom ring can be determined by the width of the palpebral fissure. We measured the width of the palpebral fissure in 72 eyes preoperatively and examined the correlation between the width of the palpebral fissure and the size of the bottom ring of the device that was actually attached to each patient. The width of the palpebral fissure was defined as the linear distance between the medial canthus and the lateral canthus. The width of the palpebral fissure was positively correlated with the size of the bottom ring $(P<0.0001)$ (Figure 3$)$. For a patient with a palpebral fissure width of $26 \mathrm{~mm}$, the device with a $25 \mathrm{~mm}$ or $26 \mathrm{~mm}$ bottom ring could be attached.

\section{Attachment}

After the administration of $4 \%$ lidocaine eyedrops, the LiDrape was attached by first pulling up the upper lid while folding the top ring and then, successively inserting the bottom ring into the upper conjunctival sac and into the lower conjunctival sac (Figure 4). The novel device was easily removed by reversing the attachment procedure.
Front view

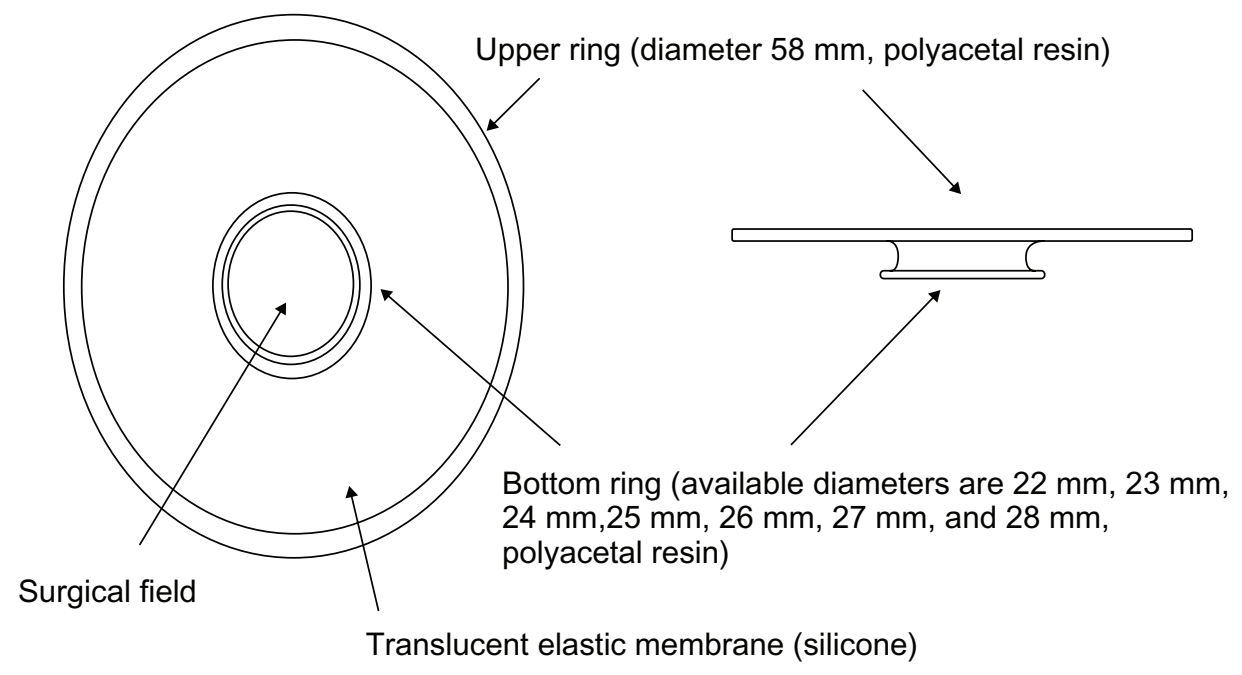

Figure I The diagram of a novel lid speculum with a drape (LiDrape $\left.{ }^{\circledR}\right)$.

Note: The cylindrical device consists of two rings of polyacetal resin and a transparent elastic silicone sheet. 

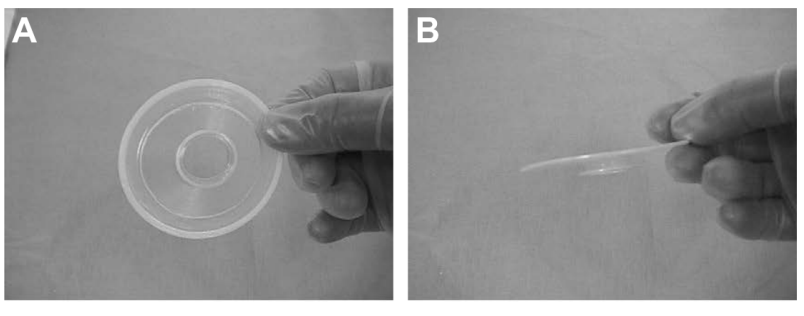

Figure 2 LiDrape ${ }^{\circledR}$. (A) Front view. (B) Side view.

\section{Cataract surgery}

LiDrape was used in 75 eyes of 70 patients who underwent phacoemulsification and aspiration (PEA) and intraocular lens (IOL) implantation. The device with a $25 \mathrm{~mm}$ or $26 \mathrm{~mm}$ bottom ring was most commonly used. The PEA and IOL implantation procedures were completed uneventfully using the device. The novel device provided a sufficient operative field (Figure 5). No detachment of the device was seen in any cases, and the surgical maneuvers proceeded without difficulty. However, excess irrigation fluid tended to pool in the surgical field, which was aspirated by an assistant.

\section{Atopic cataract}

Of 75 eyes of 70 patients who underwent PEA and IOL implantation, seven eyes of six patients had atopic cataract. Figure 6A shows the eye of a 38-year-old man with atopic dermatitis, before preoperative disinfection. The skin was dry and a large amount of secretion from the meibomian glands was seen. Figure 6B shows the same patient, with the device in place. The eyelids were completely draped, and

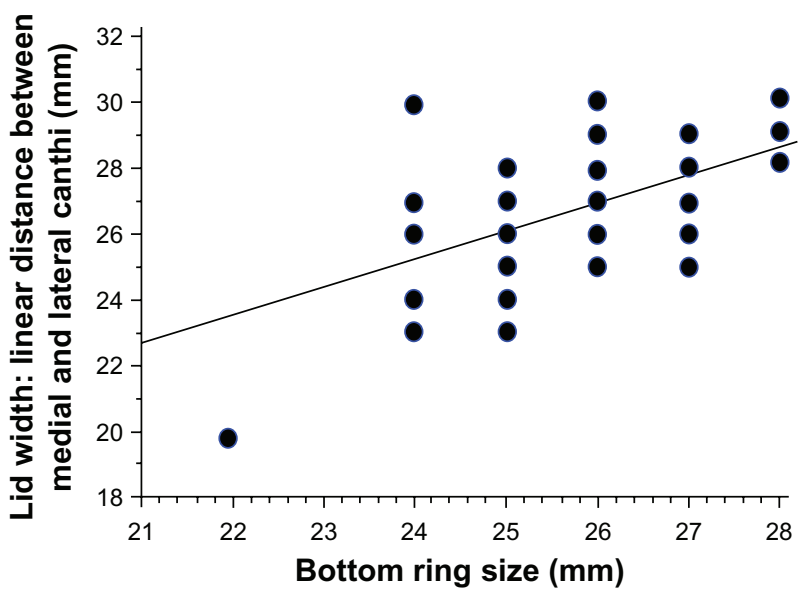

Figure 3 The correlation between the width of the palpebral fissure and the size of the bottom ring of the novel device that was used for each patient.

Notes: $Y=0.817 X+5.643 ; R=0.548 ; P<0.000$ I. Spearman's rank correlation coefficient $(n=72)$.
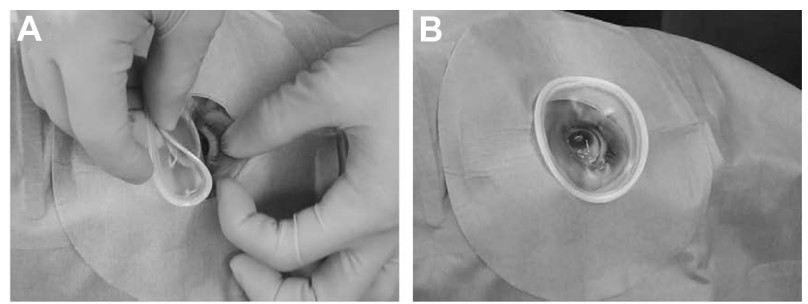

Figure 4 LiDrape ${ }^{\circledR}$ attachment procedure. (A) The device was attached by pulling up the upper lid while folding the top ring and inserting the bottom ring into the upper conjunctival sac and then into the lower conjunctival sac. (B) The device attached to the eye.

the surgical field was isolated from eyelashes and secretion. The novel device provided a sufficient surgical field and was not detached by patient blinking.

\section{Glaucoma surgery}

The LiDrape was used in eleven eyes of eleven patients who underwent fornix-based trabeculectomy. A device with either a $25 \mathrm{~mm}$ or $26 \mathrm{~mm}$ bottom ring was used. A corneal traction suture was placed and secured to the top ring of the device. The globe was rotated inferiorly to expose the superior conjunctiva. The device did not interfere with surgical maneuvers, including iridectomy (Figure 7A). A filtering bleb formed immediately after surgery (Figure 7B).

\section{Vitrectomy}

The LiDrape was used in ten eyes of ten patients who underwent 23-gauge vitrectomy. A device with either a $27 \mathrm{~mm}$ or $28 \mathrm{~mm}$ bottom ring was used. Figure 8 shows a vitrectomy for a macular hole, using the novel device with a $28 \mathrm{~mm}$ bottom ring. The surgical field was limited due to the presence of cannulas, closure valves, and a chandelier light (Figure 8A). Although the rotation of the globe was restricted, the peripheral vitreous could be completely removed with scleral indentation, under a wide-angle viewing system (Figure 8B).
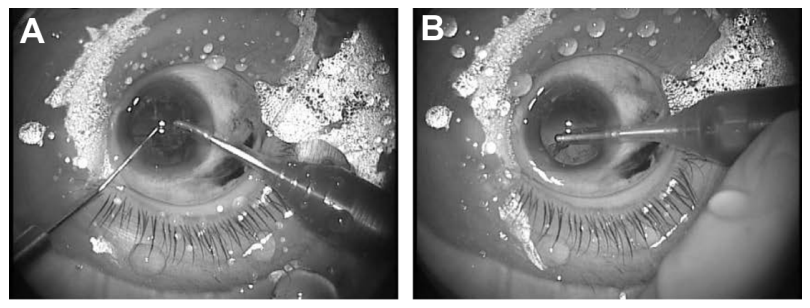

Figure 5 LiDrape ${ }^{\circledast}$ in PEA and IOL implantation. (A) Chopping and aspiration of the nucleus, using ultrasound. (B) Cortex aspiration.

Abbreviations: IOL, intraocular lens; PEA, phacoemulsification and aspiration. 

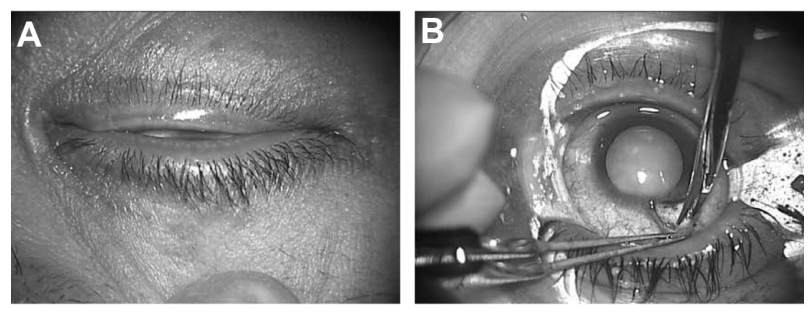

Figure 6 The eye of a 38-year-old man with atopic dermatitis. (A) The eyelid margins before preoperative disinfection. The skin was dry, and a large amount of secretion from the meibomian glands was seen. (B) The eyelashes and the eyelids were completely draped.

\section{Intravitreal injection}

The LiDrape was used in six eyes of six patients who underwent intravitreal injection of anti-VEGF drugs. A device with a $24 \mathrm{~mm}, 25 \mathrm{~mm}, 26 \mathrm{~mm}, 27 \mathrm{~mm}$, or $28 \mathrm{~mm}$ bottom ring was used. The conjunctiva was displaced with a sterile cotton swab or forceps, and an intravitreal injection of bevacizumab was performed $3.5 \mathrm{~mm}$ from the limbus (Figure 9). Conventionally, we usually apply Tegaderm ${ }^{\mathrm{TM}}$ (3M, St Paul, MI, USA) transparent dressing over the eye before speculum placement, as a preinjection procedure to prevent the needle tip from touching the eyelashes and the eyelid margins. With the novel device, the preinjection procedures and the injection itself were easily performed.

\section{Discussion}

Draping is critical in the prevention of infectious endophthalmitis, but this has an effect on surgical maneuvers. It is difficult for inexperienced surgeons to completely drape the eyelids of older patients with narrow eyelids and patients with atopic dermatitis. The LiDrape is easy to attach and can completely drape the eyelids. Furthermore, because this novel device functions as both a drape and a speculum, draping and the placement of a lid speculum can be performed in one procedure, shortening the time of preoperative preparation. In addition, the novel device is disposable. Also, there is no need for antisepsis of a metallic lid speculum.
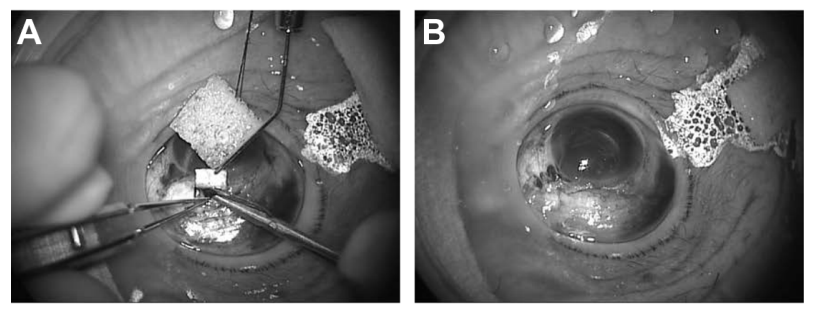

Figure 7 LiDrape ${ }^{\circledR}$ in trabeculectomy. (A) During iridectomy. (B) A filtering bleb immediately after the surgery.
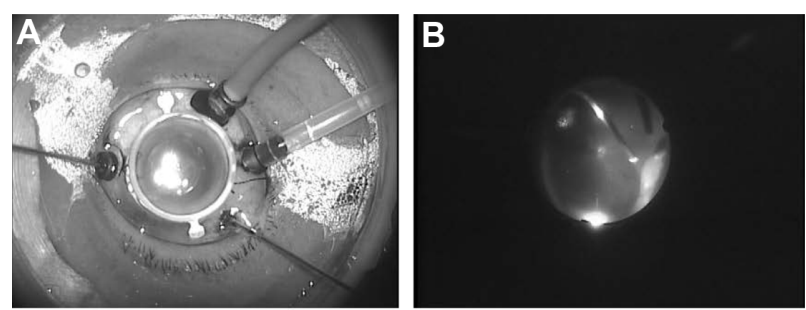

Figure 8 LiDrape ${ }^{\circledR}$ in 23-gauge vitrectomy. (A) The surgical field was limited due to the presence of cannulas, closure valves, and a chandelier light. (B) The novel device remained attached to the eye during scleral indentation under a wide-angle viewing system.

PEA and IOL implantation, the most common ophthalmic surgical procedures, were uneventfully performed in all cases. Bacteria are detected at a high frequency from the conjunctival sac and the eyelid margin, in patients with atopic dermatitis. The high rate of bacterial colonization is considered to be one of the risk factors for postoperative endophthalmitis. ${ }^{14,15}$ Conventional adhesive drapes are easily detached from atopic skin during surgery. The surgical field is then exposed to the bacteria flora on the eyelashes and the eyelids, increasing the risk for endophthalmitis. The LiDrape firmly attached to the skin of atopic dermatitis patients, and no detachment was seen during surgery. This is therefore, potentially useful for preventing infection. However, the pooling of fluid was a disadvantage of the novel device that could cause surgical field contamination. In our cases, the fluid was aspirated by an assistant, and the surgeries were completed uneventfully. To solve this problem, a disposable drain that automatically evacuates fluid is in development.

The new device could be used in trabeculectomy that involves conjunctival incision at the limbus. The complications of glaucoma-filtering surgery include bleb-related infection ${ }^{16}$ and endophthalmitis immediately after surgery. ${ }^{1}$ Glaucoma surgery takes a longer time than does cataract surgery, and a lid speculum with a drape that can prevent bacteria from gaining access to the operative field is useful. In addition, we have shown that a corneal traction suture
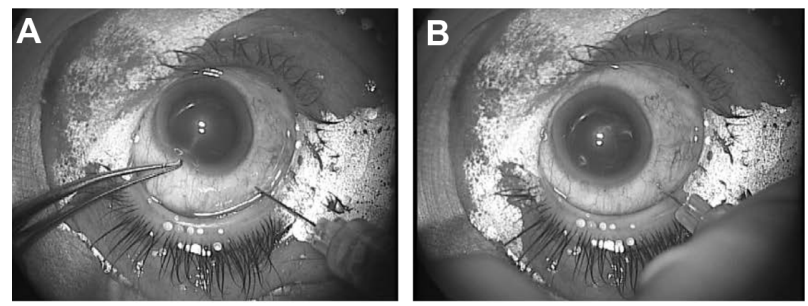

Figure 9 LiDrape $^{\circledast}$ in intravitreal injection. (A) Injection performed $3.5 \mathrm{~mm}$ from the limbus. (B) The eyelashes and the eyelids were completely draped. 
could be secured to the top ring of the device and the globe rotated to provide a sufficient surgical field.

Recently, 23- or 25-gauge transconjunctival sutureless vitrectomy has become a popular common procedure. The incidence of endophthalmitis after microincision vitrectomy is comparable with that of 20-gauge vitrectomy. ${ }^{17,18}$ Similar to endophthalmitis following cataract surgery, endophthalmitis after vitrectomy is caused by ocular surface bacteria that gain access to the vitreous cavity. ${ }^{6,18,19}$ From this perspective, the LiDrape can be useful in preventing endophthalmitis because the device isolates the surgical field from the eyelashes and secretions, during surgery. However, rotation of the globe in the surgical field provided by the $28 \mathrm{~mm}$ bottom ring was somewhat restricted. Scleral indentation under a wide-angle viewing system was helpful in performing the vitreous procedure.

Recently, intravitreal injection of various anti-VEGF drugs or triamcinolone acetonide has gained popularity. The incidence of endophthalmitis per injection of antiVEGF agent has been reported to be $0.019 \%$ to $0.077 \%{ }^{20-23}$ Anti-VEGF therapy requires multiple injections, and the incidence per eye might be higher. Infectious endophthalmitis is caused by the patient's own flora from the skin, conjunctival sac, or meibomian glands. Diago et al reported that the use of preoperative povidone-iodine drops and the use of a sterile lid speculum are important for endophthalmitis prophylaxis. ${ }^{23}$ The LiDrape easily and completely drapes the eyelashes and the eyelids. It also provides a sufficient surgical field for intravitreal injections. Intravitreal injection has been performed in many patients, on a daily basis as an office-based procedure. The LiDrape is disposable. An ophthalmic clinic does not need to prepare many sterile metallic lid specula for intravitreal injections. With the novel LiDrape, placement of a drape and a speculum is performed at once. The preinjection preparation time is short. The LiDrape is thus useful for intravitreal injection.

A prospective study is underway, to refine the device and to evaluate its efficacy in preventing surgical field contamination during cataract surgery; there, we will compare the results of the LiDrape with those of the conventional lid speculum.

\section{Acknowledgment}

This study was partially supported, in 2008, by the Japanese Ministry of Education, Culture, Sports, Science and Technology, City Area Program (Development Stage).

\section{Disclosure}

Yukihiko Tamai and Shoichiro Nakamura are full-time employees of the company that makes the novel speculum used in this study. The authors report no other conflicts of interest in this work.

\section{References}

1. Kattan HM, Flynn HW Jr, Pflugfelder SC, Robertson C, Forster RK. Nosocomial endophthalmitis survey. Current incidence of infection after intraocular surgery. Ophthalmology. 1991;98(2):227-238.

2. Speaker MG, Milch FA, Shah MK, Eisner W, Kreiswirth BN. Role of external bacterial flora in pathogenesis of acute postoperative endophthalmitis. Ophthalmology. 1991;98(5):639-649.

3. De Kaspar HM, Chang RT, Shriver EM, et al. Three-day application of topical ofloxacin reduces the contamination of microsurgical knives in cataract surgery: a prospective randomized study. Ophthalmology. 2004;111(7):1352-1355.

4. Inoue $Y$, Usui $M$, Ohashi $Y$, Shiota $H$, Yamazaki T; Preoperative Disinfection Study Group. Preoperative disinfection of the conjunctival sac with antibiotics and iodine compounds: a prospective randomized multicenter study. Jpn J Ophthalmol. 2008;52(3):151-161.

5. Apt L, Isenberg S, Yoshimori R, Paez JH. Chemical preparation of the eye in ophthalmic surgery. III. Effect of povidone-iodine on the conjunctiva. Arch Ophthalmol. 1984;102(5):728-729.

6. Ciulla TA, Starr MB, Masket S. Bacterial endophthalmitis prophylaxis for cataract surgery: an evidence-based update. Ophthalmology. 2002; 109(1):13-24.

7. Lusk JE, Lanier JD. The incise drape. Ophthalmic Surg. 1980;11(10): $722-724$.

8. Buzard K, Liapis S. Prevention of endophthalmitis. J Cataract Refract Surg. 2004;30(9):1953-1959.

9. Nagaki Y, Hayasaka S, Kadoi C, et al. Bacterial endophthalmitis after small-incision cataract surgery. Effect of incision placement and intraocular lens type. J Cataract Refract Surg. 2003;29(1):20-26.

10. Cooper BA, Holekamp NM, Bohigian G, Thompson PA. Case-controlled study of endophthalmitis after cataract surgery comparing sclera tunnel and clear corneal wounds. Am J Ophthalmol. 2003;136(2):300-305.

11. Mayer E, Cadman D, Ewings P, et al. A 10 year retorospective survey of cataract surgery and endophthalmitis in a single eye unit: injectable lenses lower the incidence of endophthalmitis. Br J Ophthalmol. 2003; 87(7):867-869.

12. Lehmann OJ, Thompson JP, White LO, Keys MF, Campbell MJ. Halflife of intracameral gentamicin after phacoemulsification. $J$ Cataract Refract Surg. 1997;23(6):883-888.

13. Endophthalmitis Study Group, European Society of Cataract and Refractive Surgeons. Prophylaxis of postoperative endophthalmitis following cataract surgery: results of the ESCRS multicenter study and identification of risk factors. J Cataract Refract Surg. 2007;33(6):978-988.

14. Nakata K, Inoue Y, Harada J, et al. A high incidence of Staphylococcus aureus colonization in the external eyes of patients with atopic dermatitis. Ophthalmology. 2000;107(12):2167-2171.

15. Miño de Kapar H, Shriver EM, Nguyen EV, et al. Risk factors for antibiotic-resistant conjunctival bacterial flora in patients undergoing intraocular surgery. Graefes Arch Clin Exp Ophthalmol. 2003;241(9): 730-733.

16. Yamamoto T, Kuwayama Y; Collaborative Bleb-Related Infection Incidence and Treatment Study Group. Interim clinical outcomes in the collaborative bleb-related infection incidence and treatment study Ophthalmology. 2011;118(3):453-458.

17. Oshima Y, Kadonosono K, Yamaji H, et al; Japan Microincision Vitrectomy Surgery Study Group. Multicenter survey with a systematic overview of acute-onset endophthalmitis after transconjunctival microincision vitrectomy surgery. Am J Ophthalmol. 2010;150(5):716-725. 
18. Wu L, Berrocal MH, Arévalo JF, et al. Endophthalmitis after pars plana vitrectomy: results of the Pan American Collaborative Retina Study Group. Retina. 2011;31(4):673-678.

19. Scott IU, Flynn HW Jr, Dev S, et al. Endophthalmitis after 25-gauge and 20-gauge pars plana vitrectomy: incidence and outcomes. Retina. 2008;28(1):138-142.

20. Mason JO 3rd, White MF, Feist RM, et al. Incidence of acute onset endophthalmitis following intravitreal bevacizumab (Avastin) injection. Retina. 2008;28(4):564-567.
21. Pilli S, Kotsolis A, Spaide RF, et al. Endophthalmitis associated with intravitreal anti-vascular endothelial growth factor therapy injections in an office setting. Am J Ophthalmol. 2008;145(5):879-882.

22. Fintak DR, Shah GK, Blinder KJ, et al. Incidence of endophthalmitis related to intravitreal injection of bevacizumab and ranibizumab. Retina. 2008;28(10):1395-1399.

23. Diago T, McCannel CA, Bakri SJ, Pulido JS, Edwards AO, Pach JM. Infectious endophthalmitis after intravitreal injection of antiangiogenic agents. Retina. 2009;29(5):601-605.
Clinical Ophthalmology

\section{Publish your work in this journal}

Clinical Ophthalmology is an international, peer-reviewed journal covering all subspecialties within ophthalmology. Key topics include: Optometry; Visual science; Pharmacology and drug therapy in eye diseases; Basic Sciences; Primary and Secondary eye care; Patient Safety and Quality of Care Improvements. This journal is indexed on

\section{Dovepress}

PubMed Central and CAS, and is the official journal of The Society of Clinical Ophthalmology (SCO). The manuscript management system is completely online and includes a very quick and fair peer-review system, which is all easy to use. Visit http://www.dovepress.com/ testimonials.php to read real quotes from published authors. 